form $A \wedge A D E$ ENISK

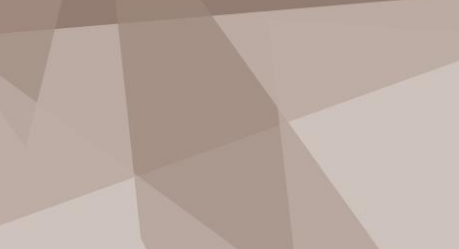

Päivi Fernström

PhD, Docent

University of Helsinki paivi.fernstrom@helsinki.fi

Vol I4, No 2 (2O2I)

Mikaela Dahlberg

Master's student University of Helsinki mikaela.dahlberg@helsinki.fi

Eeva-Leena Sirviö

Master's student

University of Helsinki eeva-leena.sirvio@helsinki.fi

Henna Lahti

Phd, Docent

University of Helsinki henna.lahti@helsinki.fi

\title{
Crafting short films
}

\section{Narrative and reflective perspectives on making in craft}

\begin{abstract}
In this article, we focus on film making as a part of craft studies and narrative inquiry. Short films were created in a course in the craft teacher master's degree at the University of Helsinki. The aim of the course was to serve several purposes such as 1) to enable students to become familiar with a new way of deepening conceptual thinking through making, 2) to apply and develop craft skills in working on a selected concept or theme, and 3) to understand the dialogue between conceptual and material artefacts. We explore the opportunities to transmit multisensory experiences via short films. For illustration, we introduce two short films created during the course. Using the deliberative interviewing method, we have broadened the perspective on reflective and analytical level.
\end{abstract}

Keywords:

Autoethnography, deliberative interviewing, film making, narratives, sensory ethnography

\section{INTRODUCTION}

Academic craft studies are now being touched by digital storytelling (Kouhia, 2015; Lahti \& Fernström, forthcoming). With respect to higher education, Fenwick (2016) points out that students and educators ought to improve their skills in using social media, or to broaden societal issues of trends and transformations wrought through digital cultures. Furthermore, Rutten (2016) encourages focusing on ethnographic research and exploring whether there may be new ways of conceptualizing in contemporary media ecology. Therefore, we study how film making give rise to arguments and findings, and how these short films can lead to research questions being originated and reflective perspectives being sustained. 
The personal experience of the artist as researcher has been stressed as an integral part of the practiceled research, which has led to several self-reflexive research projects in which artists/researchers used their own experience as part of their research (Farber \& Mäkelä, 2010; Rutten, 2016). As a research method, the aim with autoethnography is to describe and systematically analyze (graphy) personal experience (auto) in order to understand cultural (ethno) experience (Adams et al., 2015). A researcher uses tenets of autobiography and ethnography to do and write autoethnography. Thus, autoethnography is both process and product (Ellis et al., 2010). As a process, in ethnography, a culture's practices, values and beliefs are studied with the aim of helping both insiders and outsiders to understand a culture better (Rutten, 2016, p. 300). In academic education, autoethnographic exercises prove to be an effective way to teach students how to do cultural or craft-based research using their senses. According to Ehn (2011, p. 61), students are often excited by their new ability to see or hear or smell something in places other than in situations they thought they were familiar with.

\section{ETHNOGRAPHY AND FILM MAKING}

Pink (2009) introduced sensory ethnography as a methodology through theoretical grounding and case study presentation of innovative ethnographic methods. She has suggested that a sensory ethnography can be of use not only in discipline-specific projects and in applied research, but also in projects that bridge the divide between applied and academic work, and in projects that develop and combine perspectives and aims of different disciplines in interdisciplinary analysis. Pink provided a way of thinking about and doing ethnography that takes as its starting point the multi-sensoriality of experience, perception, knowing and practice. We agree with Pink (2009) that:

Through a focus on the senses and the experiential, academic and applied researchers and artists might potentially collaborate at the boundaries or intersections of their already interlinked fields of practice. A project in sensory ethnography might well produce a contribution to interdisciplinary theory building, an applied intervention and an artwork. As such, it would have the potential to communicate to a range of different audiences, using different media, and creating different sensory strategies through which to invoke the experience of one person or persons to others. (Pink, 2009)

Sensory ethnographic data production is based on observations of sensory experiences on one hand, and on bodily experiences on the other. The human body reacting to the external environment serves as an information source. By observing bodily reactions and sensory reactions, it is possible to interpret one's own experiences and those of others. In this way, one can find channels to understand their lives, values and experiences (Ellis et al., 2010; Pink, 2009; Rutten 2016).

In her dissertation Skill of Knitting, Rauhala (2019) used a research method inspired by autoand sensory ethnography which she calls "ethnography of skill". This method is based on ethnographic knowledge creation and interpretation that does not solely focus on reporting cultural phenomena but acts as a tool for fact finding and interpretation which by itself builds cultural interpretation. Rauhala (2019) used the autoethnographic approach by knitting replicas of museal mittens. By doing this she strived to understand the skills required by knitting and how the bodily knitting process felt. This she did by relating herself to the sensory and other experiences of a person knitting. In the ethnography of skill, facts and interpretation are formed by the verbalized and tacit knowledge of the researcher and their interactions. In such research, the essential factor is about interpretation that is based on the interaction between the research data, the researcher and their positioning in wider relationships. However, interpretation in this context is not meant as a subjective stream of thought but is determined by emerging meanings which have been considered against prevailing pre-conceptions and are deepened and refined during the research process (see Ehn, 2011; Rauhala, 2019).

Kouhia (2015) has studied herself as a young craft hobbyist in an autoethnographic film project entitled Crafts in My Life. Kouhia selected a craft technique close to her heart, knitting. In the short film, Kouhia knits woollen socks and relates this to contemporary do-it-yourself phenomena as well as to nostalgic, grandmother-like craft. The focus in the film was not in documenting the work process but it was a reflective, sensitive, and narrative approach to the phenomenon under study. Making the film 
provided a tool to describe her own experiences as a maker and the subjective meanings inherent to craft. Kouhia (2015, p. 280) believes that this kind of reflection is needed in the contemporary craft world, where more and more actions and connections are performed online with the aid of digital tools. In her words, "the practice may be re-viewed, reassessed, and reconceptualized, the meanings played (with) and the actions paused, rewound, and fast-forwarded-and released online".

Woermann (2018) stated in the ethnographic research context that research films are a viable option to a classic monograph by allowing enhanced understanding and analysis of issues and practices that are difficult to put into words. Wood and Brown (2012) have shown how the creative arts practice of film making can contribute to the understanding of sensory or affective knowledge in qualitative research. Their use of film is not meant to coincide with the written scholarly record but rather to highlight the vitality of their immediate experience. Based on Bruce's (2009) observations video making can bring new dimensions to the level of the students' thinking as making a video is a complex, recursive process that allows for sequential multimodal representation of thoughts and ideas. While using video making with students, he noticed four positive aspects: video allows for the expansion of compositional choices; it demonstrates the verisimilitude of students' initial concept to videotaped image; it highlights the visuality in students' re-presentations of ideas; and it provides research methodological considerations.

In our educational research context, we are interested in How can film making be used to support narrative inquiry in craft science?

\section{RESEARCH CONTEXT}

In this research initiative, we have focused on film making as a part of craft studies and narrative inquiry. Narrative inquiry carries with it a view of the phenomenon of experience. It is both the phenomenon under study and the methodology for its study (Caine et al., 2013). Short films were created in the Materializing in craft science course (5 ECTS) that we organized for the craft teacher master's degree at the University of Helsinki. The aim of the course is to serve several purposes such as 1) to enable students to become familiar with a new way of deepening conceptual thinking through making, 2) to apply and develop craft skills in working on a selected concept or theme, and 3) to understand the dialogue between conceptual and material artefacts. The course has been run twice since its inception in 2018 and it lasts for the whole autumn term and comprises seven sessions, 26 hours in all.

At the beginning of the module, the students read three publications (Adamson, 2007; Kouhia, 2015; Nimkulrat, 2012). Each student then starts to study a craft-related problem or phenomenon that particularly motivated the student. Their task was to formulate the research question and to prepare a theoretical framework utilizing a mind map built up from literature searches. Instructions for the assignment were intentionally not detailed but were sufficiently general to allow the students to use their own imagination in the work. Each student negotiated with the collected data on his or her research topic working with various craft techniques such as embroidery, crochet, macramé, weaving, handmade paper, fabric painting, engraving and woodwork. Some of the students integrated film making into their projects.

\section{THE THEMES OF THE SHORT FILM NARRATIVES}

The discipline of creative writing has made a significant contribution to the understanding of creative practice research. The practice of screenwriting might be understood to be creative writing, and the development of a screenplay might be understood to be screen production. Based on this, Batty (2015) presented various stages of screen production: the conceptualization, development, production, and reception of a screen work. He stated that a theme can be used as a creative and collaborative tool for use in the development of a screenplay, and further as an anchor during the stages: I needed to move away from craft as an initial concern, and instead try to understand how craft can be used to tell a story - how a screenplay is a vessel for carrying, or performing, themes (Batty, p. 111). 
The research material used for this paper consists of the two short films made by two participating students Mikaela Dahlberg (2018, figure 1) and Eeva-Leena Sirviö (2019, figure 2), and reflective, deliberative interviews conducted with them.

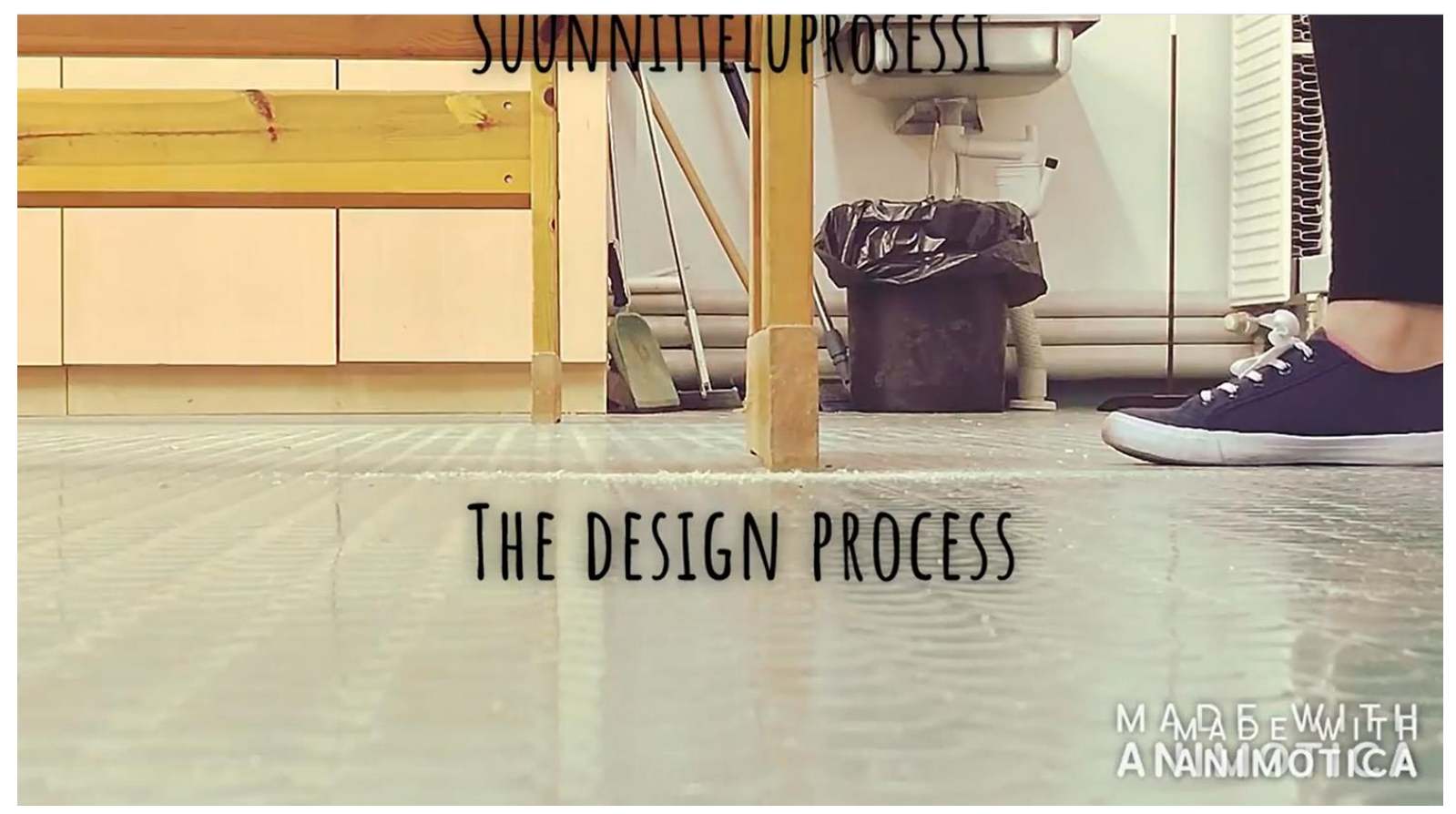

FIGURE 1. Short film 1. Dahlberg: Materialization - creating visibility or losing the visible? To watch the video, click the picture

Mikaela Dahlberg focused on the theme of material agency: Wood as a material fascinates me, since on one hand it is beautiful, natural, and sensitive, but on the other hand, it is hard and rigid. To produce a product out of wood, something needs to be carved out. Is it possible to retain its natural beauty even if it is worked on and produced into a product? How much can a piece of wood be worked until all natural and beautiful is gone?

Eeva-Leena Sirviö focused on the theme of sustainable craft: I find it is interesting that in the old days, all items had been fully consumed and it has simply been seen as a practical and as part of a more frugal lifestyle. Then mass production and excessive consumption took over because of which, use of older or self-made garments started to be regarded as poor or negative. Now, however, re-cycling and mending are fashionable and acceptable, at least among craft professionals. 


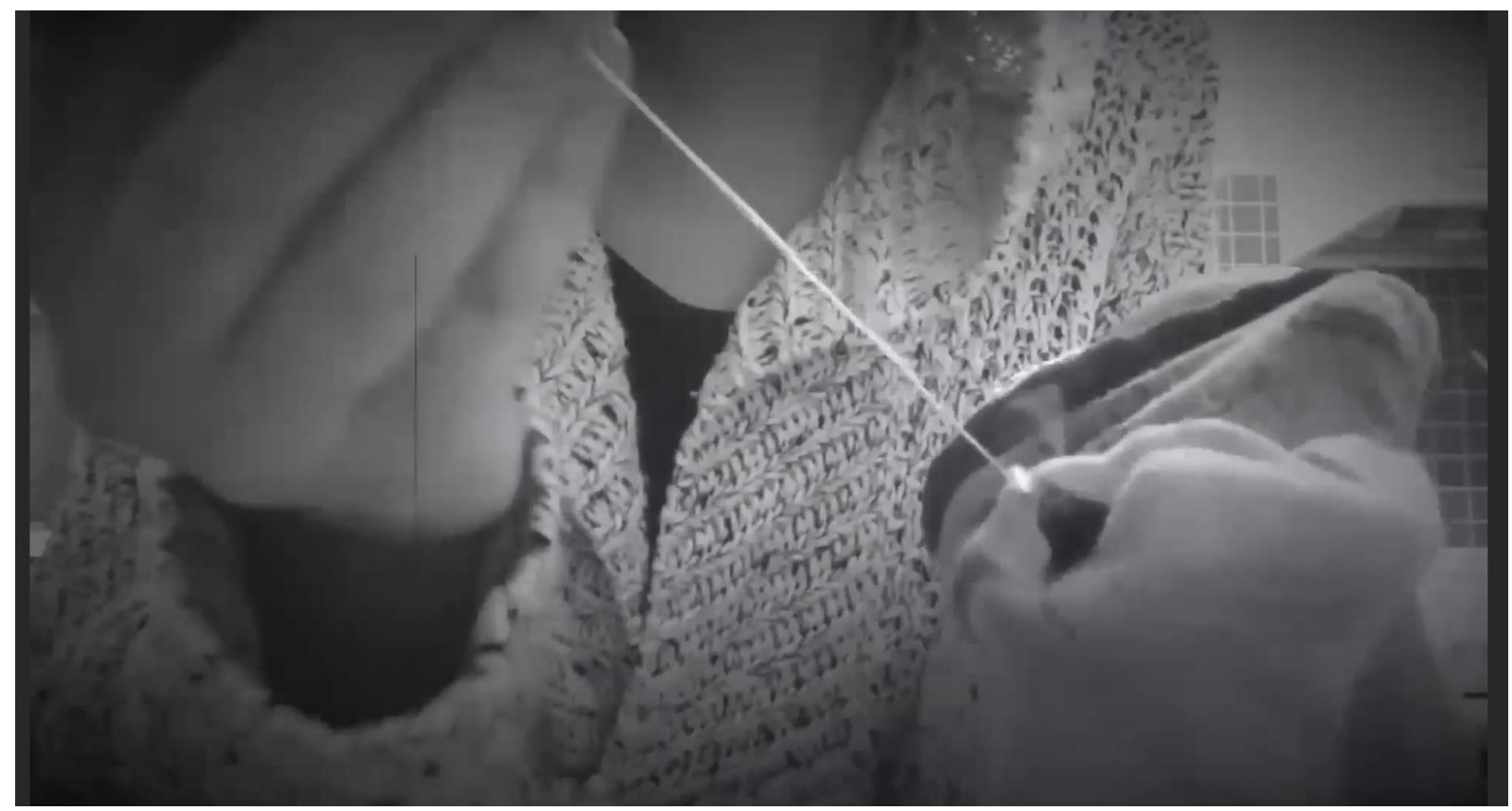

FIGURE 2. Short film 2. Sirviö: How could craft competencies be used to promote sustainable consumption and ways of life? To watch the video click the picture

In the field of sensory ethnography, senses are physical and physiological mechanisms that are activated and used in relation to place, time, and people (cf. Caine et al., 2013). Correspondingly, the students worked within the relational three-dimensional narrative inquiry space with dimensions of place, temporality, and sociality. Table 1 summarizes the narrative inquiry spaces in the short films.

TABLE 1. The narrative inquiry spaces in the short films of Dahlberg (short film 1) and Sirviö (short film 2).

\begin{tabular}{|l|l|l|}
\hline Theme & SHORT FILM 1 & SHORT FILM 2 \\
\hline Place & material agency (woodwork) & sustainable craft \\
\hline Temporality & woodworking classroom & working at the kitchen table \\
\hline Sociality & $\begin{array}{l}\text { whole craft process in the limited } \\
\text { timeframe }\end{array}$ & $\begin{array}{l}\text { flashbacks with the old soundtrack, } \\
\text { black and white film effects }\end{array}$ \\
\hline
\end{tabular}

\section{DELIBERATIVE INTERVIEW}

An essential part of this research was the use of interviews. As an interview approach, we used a deliberative interview introduced by Berner-Rodoreda et al. (2020). Deliberative interviewing is defined as a method through which the interviewer and the interviewee jointly debate the topic under discussion, often by challenging one another, and thus co-constructing new knowledge on the issue. This method has been developed according to epistemic interviewing by adapting the concept of deliberation to the interview situation.

By using deliberative interviewing, our aim was to explore more broadly what the potential of film making as a part of narrative inquiry in craft science would be, beyond the experience of our two student-interviewees. As presented by Berner-Rodoreda et.al. (2020) we used pre-interview briefings 
in preparation for the interviews explaining the methodology used in the interview. The interview, rather than being a question-answer session, was about debating the topic between the participants. We used a set list of questions, but we emphasized that each participant, two interviewers and two interviewees, was expected to participate in the debate in equal activity. As pre-interview background material, we asked the interviewees to read one article each. The articles (Aktaş \& Mäkelä, 2019; Väänänen et al., 2018) were selected with the view of inspiring the interviewees further in their respective short film projects.

The interview took place in March 2020. The duration of the interview was two hours and the entire interview was voice recorded. The list of discussion starter questions included three areas of discussion: (1) Why short film was selected as the tool for materialization (2) The use of short film to develop concept understanding and (3) The usefulness of the pre-reading article - whether the articles helped in reflecting on the use of videos in craft learning.

In studying and understanding experience narratively, we recognize the centrality of relationships. Individual narratives are situated and understood within larger cultural, social, familial, and institutional narratives (cf. Caine et al., 2013). Each story is always partial and contextual and offers new opportunities as the stories are retold. In the following, we "retell narratives" and present findings from the interview.

\section{RETOLD NARRATIVES TO DEEPEN THE STUDY OF CRAFT SCIENCE - RESULTS Transmitting multisensory experiences via short films}

Autoethnographic film making offered a way to create an evocative personal narrative of the experiences of the maker subject. Mikaela wanted to show what her design process is really like: By filming my own craft process, I proved to myself (and others), what that process includes. As shown by the film and the process description (mind map), the process is quite diverse and extends into various levels of craft. Eeva-Leena studied how different generations have observed and applied their environments and their materials at various times. By chance, at the same time, she found out how her life is a continuation of her female relatives' lives.

Mikaela's choice of filming in her exercise was motivated by her willingness to try something new rather than traditional techniques such as making a craft object. Her approach was very much experimental. She found that filming enabled her to justify her way of working to herself. Through the film she discovered what she was doing, being more present in the doing rather than performing. To her, the process was a bodily experience and one of self-discovery. This new set-up was revolutionary to her. Eeva-Leena pondered on the multisensory aspects of making the videos: Craft is multisensorial, but I had not understood video in this way. I have to say that the emotion of making is better transferred from the video to the audience than for example the written form. The on-looker can also sense the work in progress (sewing, crocheting) in her body especially if the technique is familiar to her. Both film makers explored their subject matter through their senses, emotions, and bodily activities (cf. Pink, 2009).

The importance of sounds in both short films was unexpected. For Mikaela, the sounds of working were significant, but because of the background sounds in the classroom, she could not utilize them in her film. In Eeva-Leena's film, the voice of her great grandmother Fanni Peteri is a central part and starting point. She added voice recordings from autobiographical recordings of her great grandmother and selected particularly craft related pieces. The black-and-white color has its connections to her grandmother's context. The completely spoken text is a story from decades ago, which Eeva-Leena listens to and at the same time makes her own, sustainable handicraft of this time. This has similarities with the "ethnography of skill", as Rauhala (2019) pointed out.

Sensory ethnography allows a strong engagement with a broad range of visual, performative, and material representations (Rutten, 2016; Schneider \& Wright, 2010). Both Eeva-Leena and Mikaela highlighted how carefully one had to examine what was the most essential part of the story they wanted to emphasize. Over 60 minutes of film material, they had to compose a condensed five-minute short film. All the participants in the interview stressed the importance of condensing the message into its 
essential elements. The short films allowed a dialogue between the abstract and the concrete. In the case of Eeva-Leena's topics, sustainable development, inter-linkage of generations, tuning and identity were present. Mikaela was able to make visible the design process and the thinking behind it. The story of Mikaela's short film also includes a philosophical side. Mikaela commented that although the wood material was removed when she was carving it, it was important that in the end she put the wood chips and other rubbish into the bin. As something is made apparent, something else must disappear. At the end, she collected all parts. This is an analogy to Mikaela's design process.

Mikaela and Eeva-Leena both emphasized that it is quite easy to come up with ideas for videos. They said that filming provided a new way to reflect on one's own work in a more realistic and objective fashion. In Mikaela's words, the film enables one to reflect one's own work retroactively. One is not relying solely on memories and experiences. Eeva-Leena emphasized being able to step out of one's own work and watch it with external eyes. Film is living proof of what happened. However, film making is not just documentation of making - it is a new way of expression in craft science:

Eeva-Leena: I have acquired a new channel of expression.

Mikaela: I agree, it is a new way of expressing oneself and adding new dimensions to the expression. Film does not necessarily change what I am doing but it changes how I am expressing what I am doing.

\section{Taking a new perspective via scientific articles}

To support Mikaela's project and its context in material agency, she was asked to read an article by Aktaş and Mäkelä (2019) Negotiation between the maker and material: Observations on material interactions in the felting studio. In the context of sustainability, Eeva-Leena read an article by Väänänen et al (2018) Understanding Finnish student craft teachers' conceptions of sustainability.

Aktaş and Mäkelä (2019) have examined how craft making occurs by studying the bodily movements of the maker and movements of the material in the case of felting. They studied the process of felting from the perspective of material agency in relation to the material qualities and making space. Mikaela's finding was analogical in her film in that she studied whether material has an influence on the maker and the kind of dialogue or conversation that takes place between the maker and the material. According to her, the interaction between the maker and the material enables the maker to determine which working methods and tools are needed.

Mikaela: The cooperation of my body and mind is the result of what I did to that material. The article I read really gave words to what I was trying to bring out in my video - physicality and my own working process.

In Mikaela's project, the material agency became highly versatile. It involved the environment and the rules of working tools in woodcarving. Mikaela balanced obligations to the organization and its rules of practice when she was filming in space with precise rules for the use of different tools.

During our deliberative interview, the question of the maker's skillfulness highlighted by the article (Aktaş \& Mäkelä, 2019) was discussed. As mentioned in the article, an autoethnographic researcher strives to understand the skills required in craft and the bodily experiences related to it (see Rauhala, 2019). Mikaela pointed out the difficulty in defining a craft workers skillfulness and how it is reflected in what she does. Further, she started the discussion about the relevance of procedural knowledge.

Mikaela: I think the article defines craft science very well. One can be a craft scientist and conduct research without producing the product while concentrating on other aspects such as the process and skill levels. Having now read the article and made the film, I now think that the physical craft products are secondary from the point of view of the research. 
Päivi: I agree that the product may not necessarily be needed but I do think that a craft researcher should also own some making skills related to her research topic. It is therefore easier to access the tacit and intuitive knowledge embedded in the making and the material as well as their interaction.

Eeva-Leena: I also agree. One cannot study craft unless one is at least on some level a craft maker. This may be difficult to understand to a non-craft person.

In the study by Väänänen et. al. (2018), they revealed that "student teachers approach sustainability from different orientations: practice, product, immaterial and holistic". Their study offers a new tool for understanding the abstract concept of sustainability in higher education and suggests that sustainability can be addressed through tangible methods of craft. Eeva-Leena considered her own crafting in relation to the students in the article. Motivated by sustainability concerns, she wanted to avoid making a tangible product. She was very much against producing unnecessary "trash"; filming as an immaterial method was therefore appealing to her, also allowing a certain linkage between generations.

Väänänen et.al. (2018, p. 973) concluded that in a holistic orientation, students' descriptions of craft making ranged from materials to meaning and well-being and from cultural heritage to renewing traditions. Eeva-Leena's short film includes several approaches (material, individual, socio-cultural) not just one. She had a holistic approach with both tangible and abstract features. A lively discussion ensued during the interview:

Eeva-Leena: These short films make the abstract visible, i.e. not the product, quite like in the article that the abstract concept of sustainability becomes tangible in its craft form.

Henna: In other words, the abstract becomes concrete and the concrete abstract in these short films creating interaction.

Mikaela: What you think becomes visible by what you make with your hands. In a way, it is data transfer from the brain to the hand, which becomes execution.

Eeva-Leena: Environmental issues and climate change and the like are all such large multidimensional concepts that could cause distress. Filming could be a way to bring clarity to these questions.

Based on this study, students can transform ideas in a range of ways when crafting short films. Film making as a part of narrative inquiry can invite students to see themselves as knowledge makers who find and frame problems worth pursuing, negotiate interpretations, create new connections, and represent meanings in new ways.

\section{DISCUSSION}

In this study, we aimed to analyze and describe what could be the potential of ethnography and film making in craft science. As Ehn (2011) stated, autoethnographic research methods may include three narrative modes related to a craft project. The first narrative mode is like a manual with fine detail about materials, measurements, tools etc. The second narrative mode is based on a fictional text and the work is described subjectively including multisensory experiences and the atmosphere created by the work. The third narrative mode is like a scholarly article. Our study is like these narratives. The short films presented above are narratives in which making is shown as a subjective experience and related emotions as well as the atmosphere created by such working. In the second phase of the study, the narrative approach was extended with an analytical and reflective view (deliberative interviewing) where the short films were analyzed, and their contents were interpreted as material and sociocultural events. 
Mäkelä and Nimkulrat (2018) have stressed the need for pedagogical interventions that aim to promote the development of deep conceptual understanding of challenging concepts. According to them, the dialogue between experiential and propositional knowledge provides opportunities for testing propositional knowledge in the field of craft and design, and analyzing experiential data in connection with the relevant literature can enhance the understanding of the subject studied. Our study indicated how as practitioners, we developed knowledge and practice by engaging with reflective discussions about film making. According to Charteris and Smith (2017), transformative professional learning happens when there is a community that fosters dispositions and capacities for critical reflection and inquiry. In our case, using a deliberative interview built up an understanding of the profound impacts of digital engagements on processes of knowledge-making (cf. Fenwick, 2016).

Our study showed the interrelationships in the social and material aspects of practice denoting what Fenwick et al. (2011) describe as a sociomaterial sensibility. Sociomaterial approaches to practiceled research appear to highlight a sensibility, rather than a specified set of methods for conducting research. This requires a continual process of crafting and boundary crossing. Boundary making and marking are recognized as ways in which the world is divided and actively produced, reproduced, and transformed rather than as naturally occurring phenomena (Fenwick et al., 2011, pp. 166-167). Our understanding deepened as we retold and relieved stories over time, place, and social contexts (cf. Caine et al. 2013).

As a result, we can find similar aspects in craft practice as Fenwick (2016) presented in service industries about the relationship between professional education and learning technologies. Firstly, professional educators should consider online professionalism (i.e., e-professionalism) more critically, creatively, and experimentally than previous practitioners. Secondly, a sociomaterial focus may help students and educators to acknowledge the relationships between people, technologies, and objects. Thirdly, critical reflection brings out different effects and identities that are performed when people engage with technologies in particular ways in practice. The aspects mentioned above offer approaches that may be useful in progressing the online professionalism debate: not just for researchers but also for educators, and students.

In the future, students can be introduced to various modalities of ethnography and film making and invited to experiment with them in terms of professional objectives or problems. Then, they can be prompted to reflect on the outcomes of the process to deepen the study of craft science. 


\section{REFERENCES}

Adams, T. E., Ellis, C. \& Holman Jones, S. L. (2015). Autoethnography. Oxford University Press.

Adamson, G. (2007). Thinking through Craft. Berg. https://doi.org/10.5040/9781350036062

Aktaş, B. M., \& Mäkelä, M. (2019). Negotiation between the maker and material: Observations on material interactions in felting studio. International Journal of Design, 13(2), 55-67.

Batty, C. (2015). A screenwriter's journey into theme, and how creative writing research might help us to define screen production research. Studies in Australasian Cinema, 9(2), 110-121. https://doi.org/10.1080/17503175.2015.1059991

Berner-Rodoreda, A., Bärnighausen, T., Kennedy, C., Brinkmann, S., Sarker, M., Wikler, D., Eyal, N., \& McMahon, S. A. (2020). From doxastic to epistemic: a typology and critique of qualitative interview styles. Qualitative Inquiry, 26(3-4), 291-305. https://doi.org/10.1177/1077800418810724

Bruce, D. (2009). Writing with visual images: Examining the video composition processes of high school students. Research in the Teaching of English, 43(4), 426-450.

Caine, V., Estefan, A., \& Clandinin, D. J. (2013). A return to methodological commitment: Reflections on narrative inquiry. Scandinavian Journal of Educational Research, 57(6), 574-586. https://doi.org/10.1080/00313831.2013.798833

Charteris, J., \& Smith, J. (2017). Sacred and secret stories in professional knowledge landscapes: Learner agency in teacher professional learning. Reflective Practice, 18(5), 600-612. https://doi.org/10.1080/14623943.2017.1304375

Ehn, B. (2011). Doing-it-yourself. Autoethnography of manual work. Ethnologia Europaea, 41(1), 53-63. https://doi.org/10.16995/ee.1077

Ellis, C., Adams, T.E., \& Bochner, A.P. (2010). Autoethnography: an overview. Forum: Qualitative Social Research, 12(1), Art. 10. http://nbn-resolving.de/urn:nbn:de:0114-fqs1101108

Farber, L., \& Mäkelä, M. (2010). Exploring through practice: connecting global practice-led research approaches with South African production. In L. Farber (ed.), On making: integrating approaches to practice-led research in art and design (pp. 7-18). Visual Identities in Art and Design Research Centre.

Fenwick, T. (2016). Social media, professionalism and higher education: a sociomaterial consideration. Studies in Higher Education, 41(4), 664-677. https://doi.org/10.1080/03075079.2014.942275

Fenwick, T., Edwards, R., \& Sawchuck, P. (2011). Emerging Approaches to Educational Research. Tracing the Sociomaterial. Routledge.

Kouhia, A. (2015). The making-of: An autoethnographic cinema on the meanings of contemporary craft practicing for a young hobbyist. Textile: Journal of Cloth and Culture, 13(3), 266-283. https://doi.org/10.1080/14759756.2015.1084788

Kouhia, A. (2015, Feb 24). Crafts in my life - a short film. https://www.youtube.com/watch?v=x02fmvg5yuo

Nimkulrat, N. (2012). Hands-on intellect: Integrating craft practice into design research. International Journal of Design, 6(3), 1-14.

Pink, S. (2009). Doing Sensory Ethnography. Sage. https://doi.org/10.4135/9781446249383

Rauhala, A. (2019). Neulonnan taito (Skill of Knitting). Helsingin yliopiston (Doctoral dissertation, University of Helsinki). http://hdl.handle.net/10138/307664

Rutten, K. (2016). Art, ethnography and practice-led research. Critical Arts, 30(3), 295-306. https://doi.org/10.1080/02560046.2016.1205317

Schneider, A., \& Wright, C. (2010). Between Art and Anthropology: Contemporary Ethnographic Practice. Berg.

Väänänen, N., Vartiainen, L., Kaipainen, M., Pitkäniemi, H., \& Pöllänen, S. (2018). Understanding Finnish student craft teachers' conceptions of sustainability. International Journal of Sustainability in Higher Education, 
19(5), 963-986. https://doi.org/10.1108/IJSHE-11-2017-0200

Woermann, N. (2018). Focusing ethnography: theory and recommendations for effectively combining video and ethnographic research. Journal of Marketing Management, 34(5-6), 459-483. https://doi.org/10.1080/0267257X.2018.1441174

Wood, M., \& Brown, S. (2012). Film-based creative arts enquiry: qualitative researchers as auteurs. Qualitative Research Journal, 12(1), 130-147. https://doi.org/10.1108/14439881211222787 